\title{
FIRST REPORT ON THE FEEDING BEHAVIOR OF EARLESS MONITOR, LANTHANOTUS BORNEENSIS AND ITS PREDATION ON RICE FIELD FROG, FEJERVARYA LIMNOCHARIS IN A CAPTIVE ENVIRONMENT
}

\author{
Ahmad Nauval Arroyyan ${ }^{1}$, Evy Arida*2, and Nirmala Fitria Firdhausi ${ }^{3}$ \\ ${ }^{1}$ Student at Program Studi Biologi, UIN Sunan Ampel, Jalan Ahmad Yani No.117, Surabaya 60237, Indonesia \\ ${ }^{2}$ Museum Zoologicum Bogoriense, Research Center for Biology, National Research and Innovation Agency \\ (BRIN), Jl. Raya Jakarta-Bogor Km 46, Cibinong, Bogor 16911, Indonesia \\ ${ }^{3}$ Program Studi Biologi, UIN Sunan Ampel, Jalan Ahmad Yani No.117, Surabaya 60237, Indonesia \\ *Corresponding author: evya001@brin.go.id
}

Received: 18 May 2021; Accepted: 14 December 2021; Published: 30 December 2021

\begin{abstract}
Being endemic to Borneo, the Earless monitor, Lanthanotus borneensis (Steindachner, 1878) is rarely found in its habitats due to its cryptic behavior. We provide care for confiscated animals in the Reptile House of Museum Zoologicum Bogoriense (MZB) in Cibinong, West Java, Indonesia since 2014. Little is known on its natural prey but from scattered descriptive reports. This study is aimed at documenting the feeding behavior of ten captive Earless monitors and events of predation on frogs. We set up two experiments, one with meat of Rice Field Frog, Fejervarya limnocharis, and the other with live frog of the same species. Our recorded observations ran for four weeks for the frog meat feeding experiment and followed by the frog predation experiment. Our results showed that lizards constantly accepted frog meat. Lizards tended to feed before sunset for a short period of time on the muddy soil surface, although a few individuals inconsistently fed under water. The average body mass for these lizards increased by $4.29 \mathrm{~g}$ and average SVL by $0.45 \mathrm{~cm}$. We recorded predation on frogs in three out of ten individuals observed during this study. If $F$. limnocharis is confirmed to occur in the natural habitats of L. borneensis, it is possible that this frog species is among the natural prey for Earless monitors. Further studies on its natural diets should be conducted to gain in-depth knowledge essential for generating effective captive husbandry for this nationally protected species in Indonesia.
\end{abstract}

Key words: crepuscular, frog meat, prey, reptile house, survival

\section{INTRODUCTION}

Lanthanotus borneensis (Steindachner, 1878) is an endemic lizard to Borneo and rarely found in its habitat due to its cryptic behavior. Little is known about its natural history since its description in the $19^{\text {th }}$ century. The lizard became one of the favorites among reptile hobbyists and breeders because of its rarity and unique appearance. The first record of this rare lizard in West Kalimantan, Indonesia was only in the $21^{\text {st }}$ century (Yaap et al., 2012). Following publication on new record of this enigmatic species in 2012, L. borneensis was subjected to illegal international trades. Since then, several attempts have been made to smuggle individual lizards from Kalimantan, Indonesia to destination countries in Europe. Confiscated animals from these illegal trades were sent to the Reptile House of Museum Zoologicum Bogoriense (MZB) in Cibinong, West Java, Indonesia and we have been providing care for these lizards and monitoring their behavioral conditions.

We casually feed these animals with various food items since their arrival in our facility in 2014 based on records from previous observations (Harrisson, 1961; Mertens, 1970; 
Sprackland, 1999; Mendyk, 2015; Langner, 2017). Among all the items given to the lizards, there were those not taken, including flesh of squids, one-day old mice, live freshwater fish, as well as tadpoles and froglets of Four-lined Tree Frog, Polypedates leucomystax. Interestingly, some of these lizards took the meat of Rice Field Frog, Fejervarya limnocharis despite being in a small amount. In December 2019, we re-tried to feed the lizards with meat of this frog species and were surprised to find that all frog meat provided in the tanks disappeared in the next morning (Arida, unpublished data).

This study is the first report of a larger continuing observation on the behavior of $L$. borneensis aimed at supporting the species survival in captive environment. We intend to obtain baseline data on feeding behavior and choice of food items for this protected species in Indonesia. For this reason, we have set a long-term and ongoing series of observations since 2015 to document data for further use in scientific research as well as in the initiation of exsitu conservation programs.

\section{MATERIALS AND METHODS}

\section{Animals and Management}

We conducted our observation at the Reptile House of Museum Zoologicum Bogoriense (MZB) of Indonesian Institute of Sciences (LIPI) at Cibinong Campus in West Java, Indonesia. Prior to our study, lizards have been maintained at the facility as a result of a series of confiscations in a Jakarta airport since 2014. Since then, we provided care continuously for these lizards and observed their feeding behavior regularly, although in casual manner. Several food items had been given to these lizards one at a time to see their choices for five years before this study. Those include pieces of flesh of fish, prawn, squid, crabs, snails, chicken, and frogs. Occasionally, we provided live animals such as earthworms, tadpoles, froglets, crickets, and one-day-old mice for lizards to prey on. Among the items taken was meat of the Rice Field frog, Fejervarya limnocharis. In this study, we extended our previous observation on the lizards' choice for this food item to a verification of this preference. Further, we set an experiment of predation on F. limnocharis, with aim to find evidence of intake or non-intake of the frog species as a live prey by these captive lizards.

\section{Body Measurement}

All ten Earless monitors in this study were originated from the wild and obtained through confiscation events in 2014, 2016, and 2018. Individual lizards seem to be at different level of maturity but most may have reached adult size in 2020, given their snout-vent length (SVL) 
and body mass (BM) presented in Table 1. Some of them were difficult to sex; therefore, we set the experiment regardless of sex and maturity level of these lizards.

Table 1. Body measurements of individual Lanthanotus borneensis in this study

\begin{tabular}{cccc}
\hline individual tag & Snout-Vent Length (cm) & Tail Length (cm) & Body Mass (g) \\
\hline A & 18.50 & 19.50 & 74.27 \\
B & 18.00 & 20.00 & 79.13 \\
C & 17.00 & 17.50 & 57.31 \\
D & 18.30 & 20.20 & 84.20 \\
E & 19.00 & 22.00 & 92.47 \\
F & 16.00 & 17.50 & 40.12 \\
G & 17.00 & 18.50 & 71.57 \\
H & 16.80 & 19.20 & 46.95 \\
I & 16.50 & 19.00 & 54.39 \\
J & 17.50 & 18.00 & 80.72 \\
\hline
\end{tabular}

\section{Feeding Experiment: Frog Meat}

Between January and February 2020, we continued providing meat of Fejervarya limnocharis (Fig. 1) for four weeks and recorded our observations using focal animal sampling method. The frog meat was in the form of frozen "frog legs" aimed for exports as food for humans. Each lizard individually kept in a tank was provided with 5 grams of meat of $F$. limnocharis in small chunks once every week to monitor their behavior during three observation phases, i.e. early evening, late night, and early morning. For this purpose, we specifically used a Closed-Circuit Television (CCTV) camera for two hours to monitor each individual lizard placed in a tank measuring $58.0 \mathrm{~cm}$ x $58.0 \mathrm{~cm}$ x $98.0 \mathrm{~cm}$. Each tank was set with two types of habitat, i.e. a terrestrial area with muddy soil and an aquatic area with tap water of 12-14 cm depth (Fig. 2). A camera was set over each tank and manually switched on and off for data collection. We started recording about one hour before the middle of each phase of observation, i.e. dusk (18:00), midnight (00:00), and dawn (06:00). We continued filming for another hour afterwards; therefore, film duration for each observation phase was approximately two hours. During the course of experiment in January and February 2020, sunset occurred approximately at 18:15 of Jakarta time (https://www.bmkg.go.id/tandawaktu/terbit-terbenam-matahari.bmkg), which we used as a time-point to determine the two observation sub-phases in the early evening. 
The total number of recorded observations was 24 for each lizard, which is calculated as: 3 observation phases $\times 2$ sub-phases (before and after dusk, midnight, or dawn) $\times 4$ weeks. Data on feeding status were tabulated after watching the playbacks, as well as duration of feeding.

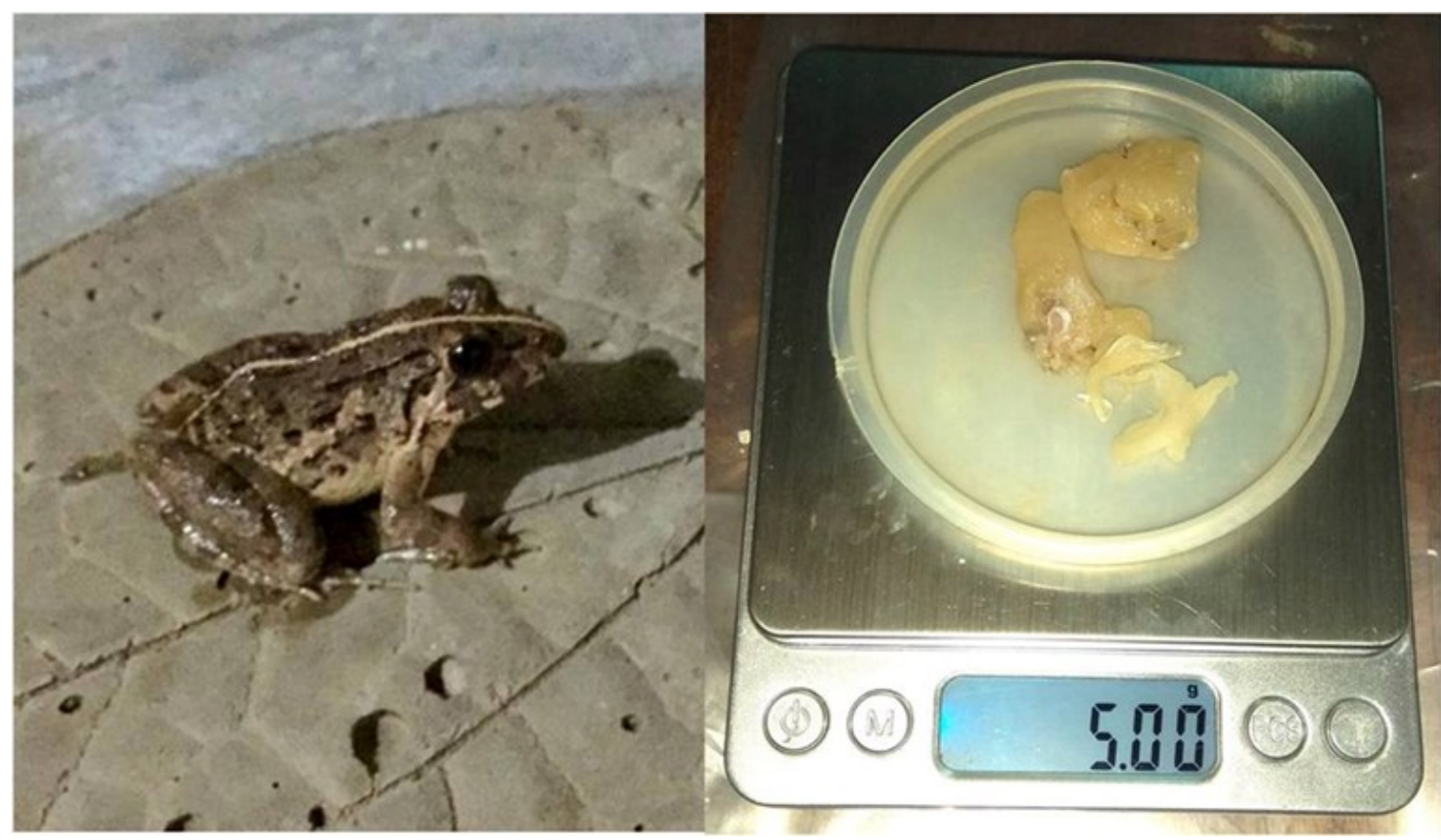

Figure 1. a. A Rice Field Frog, Fejervarya limnocharis and b. Pieces of frog meat weighed to the nearest of 5 grams.

There were ten individual lizards being monitored each week for their intake of frog meat. Each lizard was tagged with a labelled elastic cable-tie adjusted to loosely fit around the hind limbs insertion (Fig. 3), in order to identify individuals. Labelling for each individual lizard was done by alphabet "A" to "J" marked on the cable-ties.

\section{Predation Experiment: Live Frog}

Six weeks after the end of our feeding experiment, lizards were given one live frog, $F$. limnocharis (Fig. 1b.) in two weekly trial experiments. Nevertheless, we continued providing food items for the lizards at regular schedule and frequency during the interval between the two experiments. We placed each of all ten lizards into a smaller plastic container measuring $31.0 \mathrm{~cm}$ x $21.0 \mathrm{~cm}$ x $19.5 \mathrm{~cm}$ with a firm ventilated lid. A lizard and a live frog were placed in the container filled with shallow water for 20 ' before sunset. Following the sunset, we waited in silence in the absence of light for signs of predation such as a squeaking sound of a bitten frog. Predation events were recorded using a camera function of a smartphone. We tabulated data from the playbacks to describe the steps of predation. Additionally, we recorded environmental conditions, i.e. air temperature, humidity of the soil surface, and potential Hydrogen $(\mathrm{pH})$ in water. 


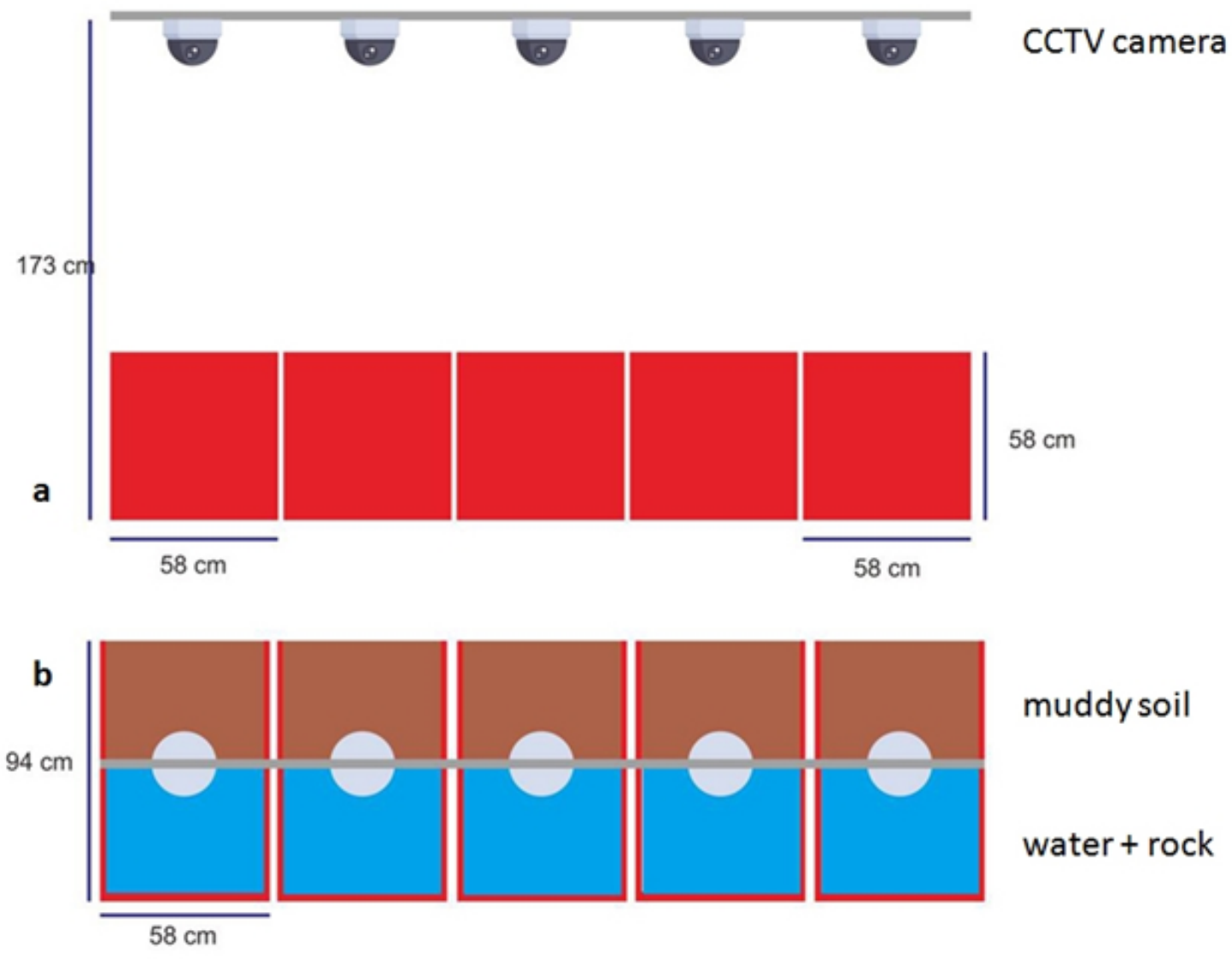

Figure 2. a. A front view and b. an above view of CCTV cameras positioning relative to the observation tanks. Each tank has a semi-natural terrestrial habitat and an aquatic habitat.

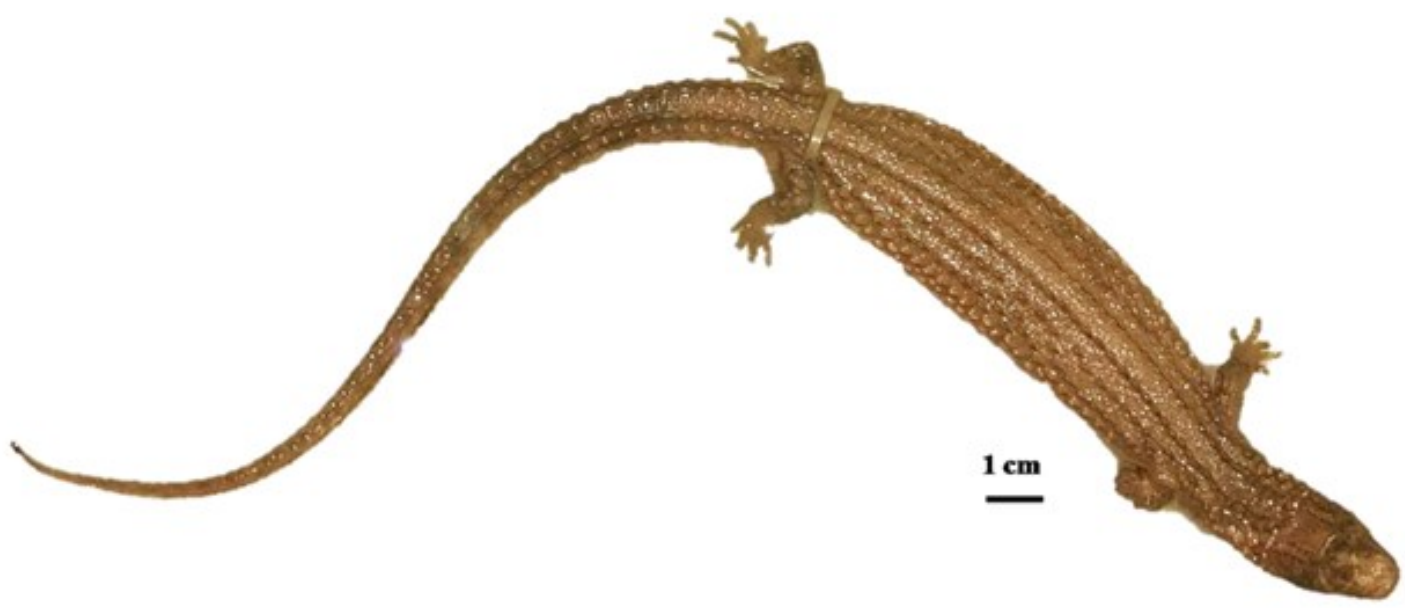

Figure 3. An individual Lanthanotus borneensis ("I") was tagged with a cable-tie around the insertion of hind limbs. 


\section{RESULTS}

\section{Body Measurements}

At the beginning of feeding experiment, mean SVL for all ten lizards was $17.45 \mathrm{~cm} \pm$ 0.95 and mean body mass was $68.11 \mathrm{~g} \pm 17.38$ (Fig. 4). Mean SVL of them was $17.90 \mathrm{~cm} \pm$ 1.19 and mean body mass was $72.40 \mathrm{~g} \pm 17.40$ at the end of this experiment. Air temperature and humidity were stable at $26^{\circ} \mathrm{C}-29^{\circ} \mathrm{C}$ and $77 \%-95 \%$, respectively. Water in all containers in this experiment was constantly with $\mathrm{pH}$ of 6.

\section{Feeding Behavior}

Lizards generally accepted frog meat consistently during the four-week observation. Regardless of body size and sex, most individuals were recorded to consume frog meat in the early evening, i.e. between 17:15 and 19:15 except individual "J". This individual was not observed feeding during the camera recording; however we found evidence that this lizard consumed frog meat during the interval between filming periods. No lizard was observed on camera feeding late at night and in the early morning hours. More specifically, lizards more frequently fed before sunset than after, with 14 versus 9 observations, respectively, on camera during the period of one month (Table 2). Each lizard tended to feed less frequently than expected, with the maximum feeding event of five for lizard " $\mathrm{B}$ " (Table 2) during the one-month experiment ( 5 of 24 or about $20.8 \%$ ).

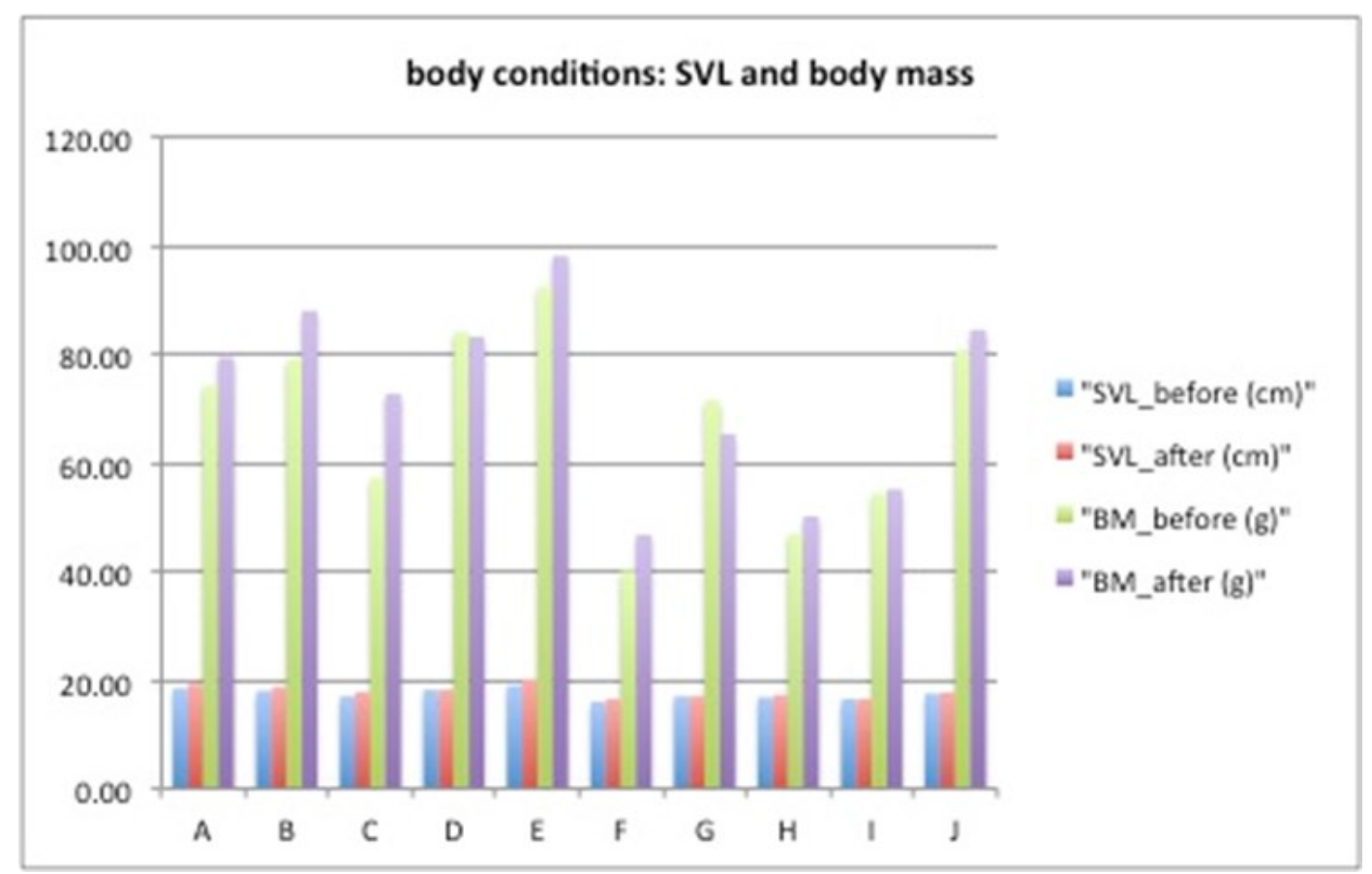

Figure 4. Body measurements of ten individual Lanthanotus borneensis before and after feeding experiment. 
We noted various frequencies of observed feeding for each lizard, i.e. 1-5 times during the experiment period. Three individuals, i.e. "A", "B", and " $D$ " were the most frequently observed feeding, i.e. 3-5 times, whereas the other six lizards were observed to feed less frequently, i.e. 1-2 times during the period of experiment (Table 2). More specifically, lizards " $\mathrm{C}$ " and " $\mathrm{H}$ " were observed feeding only in Week 3 and Week 1, respectively (Table $3)$.

Eight lizards were observed feeding in Week 3 with a total of nine observations (Table 3). Among all four weeks of observation, lizard " $\mathrm{B}$ " was consistently found feeding and lizards " $\mathrm{C}$ " and " $\mathrm{H}$ " were found feeding only in one out of the four weeks. Frequencies of observed feeding were increasing over the first three weeks of experiment, with Week 3 as the peak, when most lizards, i.e. eight individuals were observed feeding.

Except for lizards "C" and "F", all the other six lizards observed in Week 3 (Table 3) were feeding only before sunset, i.e. 6 out of total 14 observations for feeding before sunset (Table 2). Lizard "C" was feeding only in Week 3 (Table 3) but observed twice, i.e. before and after sunset (Table 2). Lizard "F" was observed to be feeding only after sunset (Table 2) in Week 3 and Week 4 (Table 3).

Table 2. Frequency distribution of feeding events across three observation phases for each lizard during four observation weeks

\begin{tabular}{cccccc}
\hline \multirow{2}{*}{ individual tag } & total frequency & \multicolumn{2}{c}{ early evening } & late night & early morning \\
\cline { 3 - 5 } & & before sunset & after sunset & & \\
\hline A & 4 & 2 & 2 & 0 & 0 \\
B & 5 & 4 & 1 & 0 & 0 \\
C & 2 & 1 & 1 & 0 & 0 \\
D & 3 & 2 & 1 & 0 & 0 \\
E & 2 & 2 & 0 & 0 & 0 \\
F & 2 & 0 & 2 & 0 & 0 \\
G & 2 & 2 & 0 & 0 & 0 \\
H & 1 & 0 & 1 & 0 & 0 \\
I & 2 & 1 & 1 & 0 & 0 \\
J & 0 & 0 & 0 & 0 & 0 \\
grand total & $\mathbf{2 3}$ & $\mathbf{1 4}$ & $\mathbf{9}$ & $\mathbf{0}$ & $\mathbf{0}$ \\
\hline
\end{tabular}


Lizards generally started to feed as early as 17:27 and as late as 18:57. Figure 5 shows container setting and condition after sunset, when lizards were feeding on camera. Lizards tended to feed on spot, where frog was contained in a small plastic tray placed on the muddy soil surface. However, this behavior was inconsistent among individuals and even within an individual. Some lizards brought one piece or more of the frog meat into the aquatic part of the container for consumption under water. Lizards "A", "B", and "D" were observed to bring their feed straight into water after they took hold of it. However, in another feeding event, lizard "B" was observed to be feeding in a spot beside a feeding tray.

Approximately 28800 seconds (4 weeks x 120 minutes x 60) were allocated to record feeding behavior of each lizard. Our study showed that lizards spent time for feeding much less than the time allocated for recorded observations. Only a small proportion of time was spent for feeding, i.e. as much as $0.85 \%$ in lizard "B" (244 of 28800 seconds). Whereas other individuals spent a smaller percentage of time for feeding than lizard "B", feeding duration for lizards "F" was the smallest $(0.17 \%)$.

In general, time for feeding seemed to peak in Week 3, except for lizards " $\mathrm{E}$ ", " $\mathrm{H}$ " and "J" (Table 4). Mean feeding duration for all lizards during the early evening was 29.32 seconds ( $\mathrm{SD}=37.29$, range: 0-115 seconds), i.e.1173: (4 x 10). For each individual lizard, mean time spent for feeding range from 2 to 61 seconds; however lizard "J" did not take any

Table 3. Frequency distribution of feeding events across four observation weeks for each lizard

\begin{tabular}{cccccc}
\hline individual tag & total frequency & Week 1 & Week 2 & Week 3 & Week 4 \\
\hline A & 4 & 0 & 2 & 1 & 1 \\
B & 5 & 1 & 2 & 1 & 1 \\
C & 2 & 0 & 0 & 2 & 0 \\
D & 3 & 1 & 0 & 1 & 1 \\
E & 2 & 0 & 1 & 1 & 0 \\
F & 2 & 0 & 0 & 1 & 1 \\
G & 2 & 0 & 0 & 1 & 1 \\
H & 1 & 1 & 0 & 0 & 0 \\
I & 2 & 1 & 0 & 1 & 0 \\
J & 0 & 0 & 0 & 0 & 0 \\
grand total & $\mathbf{2 3}$ & $\mathbf{4}$ & $\mathbf{5}$ & $\mathbf{9}$ & $\mathbf{5}$ \\
\hline
\end{tabular}



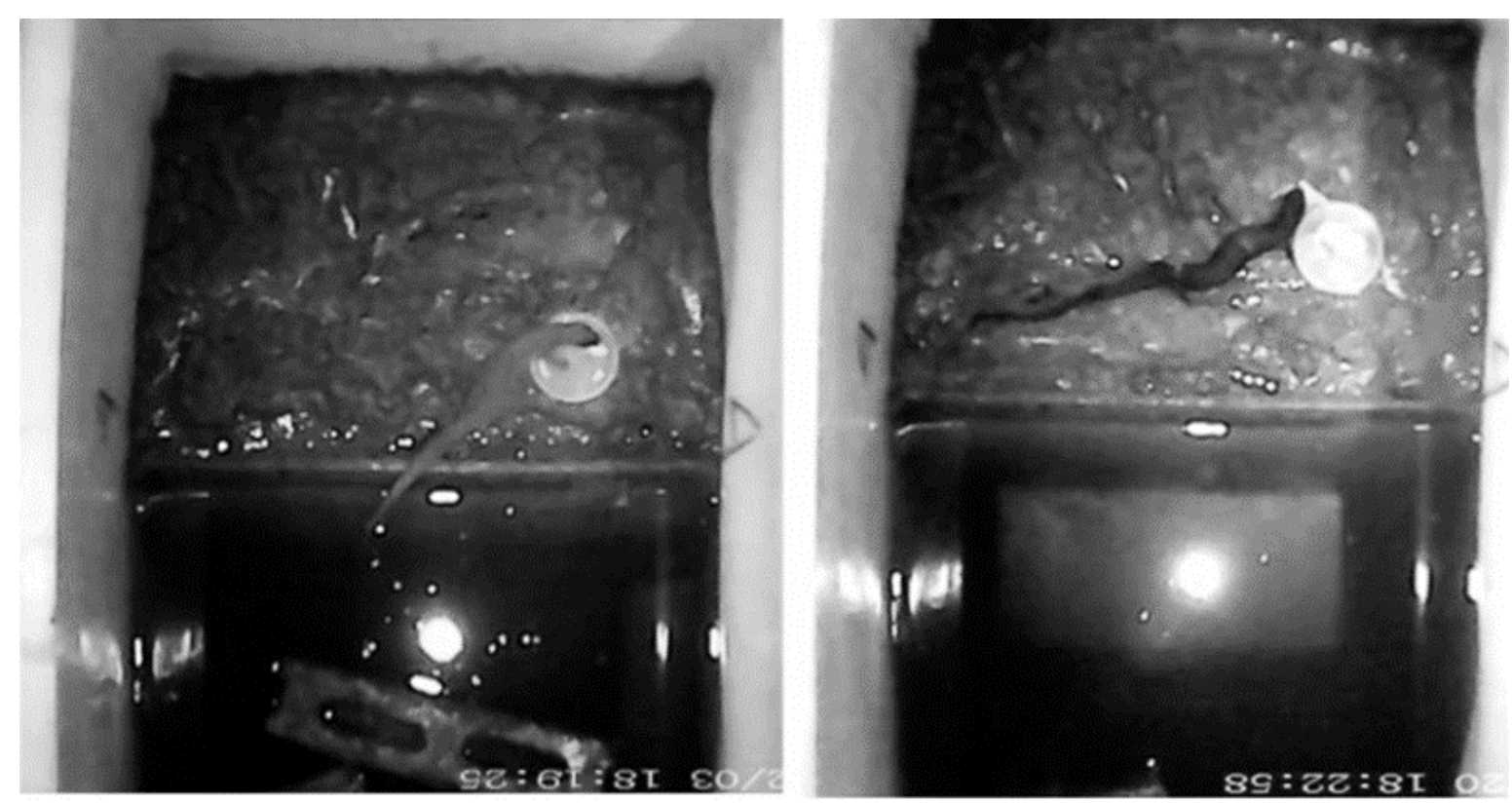

Figure 5. Individual " $B$ " (left) and " $D$ " (right) were observed feeding on frog meat after sunset. The image were taken before the lizards took the meat into the aquatic part of the experiment tank for consumption .

feed during the weekly observations. Three lizards, i.e. "D", "E" and "G" took more than 100 seconds (about 1.75 minutes) to feed during the early evening observations and fed 2-3 times during a month. On the other hand, feeding duration for lizards " $\mathrm{C}$ " and " $\mathrm{H}$ " were close to 100 seconds (about 1.5 minutes) and fed only once during the one-month experiment.

\section{Predation Events}

Predation on live frogs was successfully recorded for three individuals, i.e. "A", "E" and "G". The prey was taken by means of a grip of the upper and lower jaws for relatively long time, while the lizards shook their head to the right and left. It was probably the frog's movement that has triggered the attack; however we needed to verify this assumption using a close-up shot of a CCTV camera. The frog was slowly swallowed in whole, and seemingly no specific part of the frog was being taken first. Lizard "A" gripped the head of a live frog and remained holding the prey for 3'51" before swallowing it as a whole (Fig. 6). Similarly, lizard " $G$ " took a live frog by its head (not shown) and took 15 ' 57 " to finish eating the prey. Body masses of the frogs were $5.99 \mathrm{~g}$ and $6.12 \mathrm{~g}$ for lizards " $\mathrm{A}$ " and "G", respectively.

On the other hand, lizard "E" bit the right hind limb of the frog and swallowed it in the same position as when it was first bitten (Fig. 7). It took 20'05" for lizard "E" to consume its prey of $7.96 \mathrm{~g}$. As the frog stopped squeaking during the grip of the lizard's jaws, we assumed that it died before being swallowed. 
These lizards remained in the smaller containers overnight before they were returned to their larger tanks in the morning of the following day. Thus, our experiment on predation is specifically designed to test for only one live frog during the course of noctural period. Lizard "C" was not successfully observed preying on the live frog but did took the prey during the course of the night in the second trial week. Similarly, individuals "E" and "G" were not recorded on camera for preying on the frog in the first and second trial week, respectively. However, live frogs were absent from their closed experimental tanks. Thus, we determined the latter lizards preyed on live frogs twice during the two trial weeks.

Table 4. Duration of observed feeding during the course of experiment

\begin{tabular}{ccccccc}
\hline $\begin{array}{c}\text { individual } \\
\text { tag }\end{array}$ & $\begin{array}{c}\text { total duration } \\
\text { (seconds) }\end{array}$ & \multicolumn{2}{c}{ duration of observed feeding in the evening (seconds) } & Mean \pm SD \\
\cline { 3 - 6 } (seconds) & Week 1 & Week 2 & Week 3 & Week 4 & \\
$\mathbf{A}$ & 90 & 0 & 19 & 51 & 20 & $23 \pm 21$ \\
$\mathbf{B}$ & 244 & 52 & 41 & 67 & 84 & $61 \pm 19$ \\
$\mathbf{C}$ & 90 & 0 & 0 & 90 & 0 & $23 \pm 45$ \\
$\mathbf{D}$ & 223 & 26 & 0 & 115 & 82 & $56 \pm 52$ \\
$\mathbf{E}$ & 138 & 0 & 105 & 33 & 0 & $35 \pm 50$ \\
$\mathbf{F}$ & 49 & 0 & 0 & 8 & 41 & $12 \pm 20$ \\
$\mathbf{G}$ & 178 & 0 & 0 & 101 & 77 & $45 \pm 32$ \\
$\mathbf{H}$ & 86 & 86 & 0 & 0 & 0 & $2 \pm 43$ \\
$\mathbf{I}$ & 75 & 23 & 0 & 52 & 0 & $19 \pm 52$ \\
$\mathbf{J}$ & 0 & 0 & 0 & 0 & 0 & 0 \\
grand total & $\mathbf{1 1 7 3}$ & $\mathbf{1 8 7}$ & $\mathbf{1 6 5}$ & $\mathbf{5 1 7}$ & $\mathbf{3 0 4}$ & \\
\hline
\end{tabular}

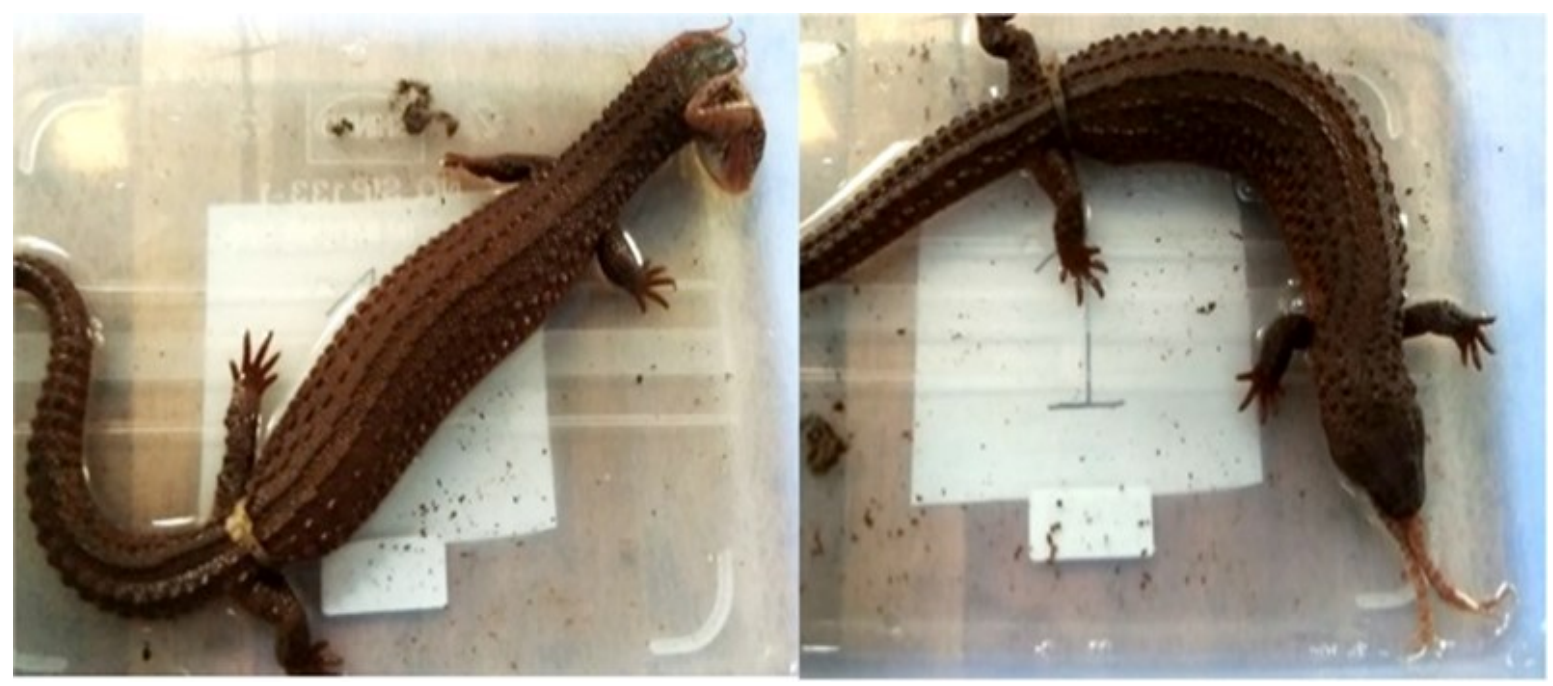

Figure 6. Individual "A" at its first attack to the head of its prey (left) and slowly swallowing it (right). 


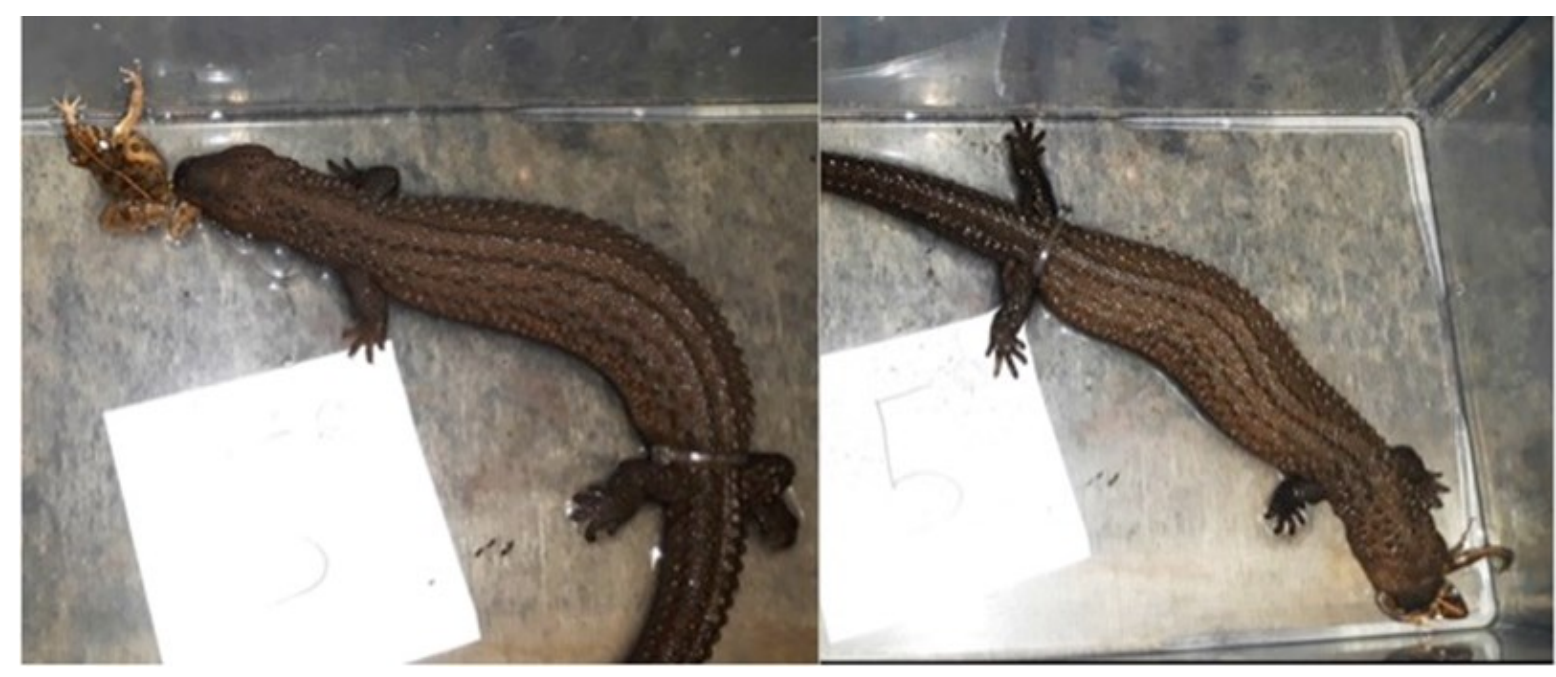

Figure 7. Individual "E" at its first attack to the right hind limb of its prey (left) and the beginning of taking the prey in whole (right)

\section{DISCUSSION}

Although L. borneensis is known to consume various items in captivity (Mendyk, 2015), wild animals of this species may specialize in commonly available preys in its natural semiaquatic habitats, for example earthworms (Arida et al., 2018). Such small ground-dwelling animal maybe one of the natural preys for L. borneensis. Therefore, we set experimental observations on feeding behavior and predation of this lizard on another small grounddwelling species for this study, i.e. F. limnocharis, which is a common frog across the western Indonesian islands. Our experiment was set in captivity due to the reclusive nature of this species, which poses great difficulties for observations in its natural habitats (Arida et al., 2018).

The Earless monitor is considered a nocturnal species (Harrisson \& Haile, 1961) and has been found active in its natural habitat in the evening at about 20:30 (Langner et al., 2017). Similarly, lizards in our study seemed to actively feed during the early hours of the evening and were consistently observed to feed on frog meat in this nocturnal phase for a few weeks. Lizards seemed to spend extremely limited time for feeding even during their putative preferred phase. For example, lizard "D" only used $\sim 1.6 \%$ of total observation time in the evening (115/7200 seconds) for feeding and was the longest to spend time feeding among all lizards in this study. Nevertheless, feeding might also took place between 19:15 and 23:00 or between 01:15 and 05:00, when lizards were not filmed for observation.

Observed feeding frequencies were variable among individuals, but feeding seemed to occur more often before sunset than after sunset across our samples (Table 2). This finding 
shows that most lizards were receptive of the feed available in the container before dark, suggesting crepuscularity rather than nocturnality. Feeding duration was also variable among individuals but generally short, with the longest being about 1.75 minutes $(1.46 \%$ of a single recorded observation).

We consider a relationship between body size and feeding behavior, in which larger lizards tend to feed repeatedly, as they probably require more nutrition than smaller lizards. Larger lizards were more commonly observed feeding, especially before sunset, and also generally more receptive to feed than smaller lizards. Three lizards with relatively large body size, i.e. SVL of at least $18.00 \mathrm{~cm}$ were found as the most frequent feeders during the course of the experiment. These lizards, i.e. "A", "B", and "D" fed mostly before the sunset, alike lizards "E" and "G", although the latter was relatively small in size, i.e. SVL=17.00 $\mathrm{cm}$. The smallest lizard "F" of SVL=16.00 cm was observed to feed only after sunset, similar to individual " $\mathrm{H}$ ", which was as small in body size with $\mathrm{SVL}=16.80 \mathrm{~cm}$ (Table 1).

It is interesting to note, that two individual lizards showed a behavior of feeding under water of some depth. In our observations, lizards seemed to feed only inconsistently under water. Lizards "A" and "D" fed on frog flesh with their whole body and head submerged under water during the frog leg experiment, whereas most other individuals fed on frog meat at the side of the container filled with muddy soil. Underwater feeding may be a behavior to reduce energy expenditure because locomotion under water is less challenging than on land (Seymour, 1982). Nevertheless, L. borneensis is semi-aquatic and may by chance adjust to a depth of water or soil surface for feeding. It is most likely that a soggy environment is simply vital for this species to survive.

We found behavioral consistency of captive L. borneensis feeding on frog meat as well as preying on live frog. Thus, F. limnocharis used in this study (Fig. 7) may represent a natural prey for this species. Lizards took much longer time to consume its live prey in whole, whereas spending relatively short period to feed on pieces of frog meat. Both our experiments suggest that regardless of live or dead, frog is a suitable diet for captive $L$. borneensis.

We noticed increased body mass for most lizards at the end of the experiment, except for two, i.e. "D" and "G". Lizards' mean body mass at the end of our observation increased by 4.29 g (Fig. 4). Among all ten lizards, individual "E" was the largest, with $19.00 \mathrm{~cm}$ of SVL and body mass of $92.47 \mathrm{~g}$ at the onset of our experiment (Table 1). This individual was found on camera feeding only at two out of four observation weeks and did take frog meat consistently before sunset (Tables 2 and 3). At the end of the experiment, this specimen 
increased its body conditions to $20.10 \mathrm{~cm}$ of SVL and $98.20 \mathrm{~g}$ of body mass. This finding shows that a relatively large L. borneensis is still at growth given a suitable habitat conditions and prey in captivity. However, increased body size was inconsistent among all lizards, probably because of factors such as discrepancies in intake and energetics of each individual.

Despite our current understanding on the consistent feeding and predation of $F$. limnocharis by L. borneensis in our captive samples, natural diet of this species remains poorly understood. Known natural prey animals to date are freshwater shrimps of the genus Macrobrachium and fish of the genus Clarias (Langner, 2017). Despite low in gross energy, earthworms seem to be also preferred by this species (Arida et al., 2018), suggesting its lethargic nature. It is possible that $F$. limnocharis occurs in the natural habitats of $L$. borneensis, as it has a wide distribution area in Southeast Asia, including in secondary forests in West Kalimantan (Kurniawan et al., 2014; Saputra et al., 2016). Therefore, along with earthworms, freshwater shrimp and fish, this frog species is likely a natural prey for the Earless monitor.

Currently, three species of frogs are known to occur in the habitats of L. borneensis in the vicinity of Serimbu Village in West Kalimantan, i.e. Limnonectes kuhlii, Ansonia spinulifer, and Leptobrachium abbotti (Arida et al., 2018). Further experimental studies to determine natural prey of L. borneensis should apply these frog species cohabiting in its habitats on Borneo. Such a study will be helpful in the formulation of diets for captive individuals. Moreover, knowledge on diets and the relevant nutritional parameters are crucial for an effective captive husbandry (Augustine et al., 2016).

In conclusion, our limited observation on the feeding behavior of L. borneensis and its predation on $F$. limnocharis suggests that this frog species is one among the lizard's natural prey animals. Nevertheless, further studies are essential to confirm this notion. We believe our current results have contributed some knowledge and a new perspective on the natural diets of L. borneensis.

\section{ACKNOWLEDGMENTS}

The authors thank officers at Bareskrim of the Indonesian National Police and $\mathrm{Bu}$ Irma of Wildlife Crime Unit (WCU) of the Wildlife Conservation Society for providing live specimens of L. borneensis from several confiscations between 2014 and 2018. We also thank Elika Boscha for his great help in our experiments at the Reptile House of MZB. The project is funded through Indonesian National Grant Scheme (DIPA) for Research Center for 
Biology LIPI under the project "Wildlife Nutrition and Captive Breeding". ANA ran the experiments and analyses, provided figures and illustrations in the manuscript; EA concepted the experiment, ran the analyses, and drafted the manuscript; NFF provided comments on the manuscript and supervised thesis writing for ANA.

\section{REFERENCES}

Arida, E., Al Ryzal, M.R., Syaripudin, S., Mulyadi, M., Handayani, T.H., Amalia, R.L.H., Rachmatika, R. \& Hamidy, A. 2018. Biawak Kalimantan, Lanthanotus borneensis: Keberadaan di alam, kondisi habitat, dan pilihan pakan [Biawak Kalimantan, Lanthanotus borneensis: Presence in nature, habitat condition, and feed preference], Prosiding Seminar Nasional Tumbuhan dan Satwa Liar, Bogor. pp. 83-91.

Augustine, L.K., Terrell, A., Petzinger, C., Nissen, B. \& Maslanka, M. 2016. Nutritional analysis of diet items available to captive and free-ranging hellbenders (Cryptobranchus alleganiensis). Herpetological Review, 47(1): 63-69.

Harrisson, B. 1961. Lanthanotus borneensis habits and observations. Sarawak Museum Journal, 10 (17-18): 286-292.

Harrisson, T. \& Haile, N.S. 1961. Notes on a living specimen of the Earless monitor lizard, Lanthonotus borneensis. Journal of Ohio Herpetological Society, 3(2): 13-16.

Kurniawan, N., Djong, T.H., Maideliza, T., Hamidy, A., Hasan, M., Igawa, T. \& Sumida, M. 2014. Genetic divergence and geographic distribution of frogs in genus Fejervarya from Indonesia inferred from mitochondrial 16S rRNA gene analysis. Treubia, 41: 1-16.

Langner, C. 2017. Hidden in the heart of Borneo-shedding light on some mysteries of an enigmatic lizard: first records of habitat use, behavior, and food items of Lanthanotus borneensis (Steindachner, 1878) in its natural habitat. Russian Journal of Herpetology, 24(1): 1-10.

Mertens, R. 1970. Zum Ernährungsproblem des Taubwarans, Lanthanotus borneensis. Salamandra, 6 (3-4): 133-134.

Mendyk, R., Shuter, A. \& Kathriner, A. 2015. Historical notes on a living specimen of Lanthanotus borneensis (Squamata: Sauria: Lanthanotidae) maintained at the Bronx Zoo from 1968 to 1976. Biawak, 9(2): 44-49.

Saputra, R., Yanti, A.H. \& Setyawati, T.R. 2016. Inventarisasi jenis-jenis amfibi (ordo Anura) di areal lahan basah sekitar Danau Sebedang Kecamatan Sebawi Kabupaten Sambas. Protobiont, 5 (3): $34-40$.

Seymour, R.S. 1982. Physiological adaptations to aquatic life. In: C. Gans \& F.H Pough, eds. Biology of the Reptilia, Physiological Ecology. Volume 13. Massachusetts: Academic Press: pp.1 -51 .

Sprackland, R.G. 1999. Sarawak's Earless monitor lizard (Lanthanotus borneensis). Reptiles, 3: 72 79.

Yaap, B., Paoli, G.D., Angki, A., Wells, P.L., Wahyudi, D. \& Auliya, M. 2012. First record of the Borneo Earless monitor Lanthanotus borneensis (Steindachner, 1877) (Reptilia: Lanthanotidae) in West Kalimantan (Indonesian Borneo). Journal of Threatened Taxa, 4(11): 3067-3070. 